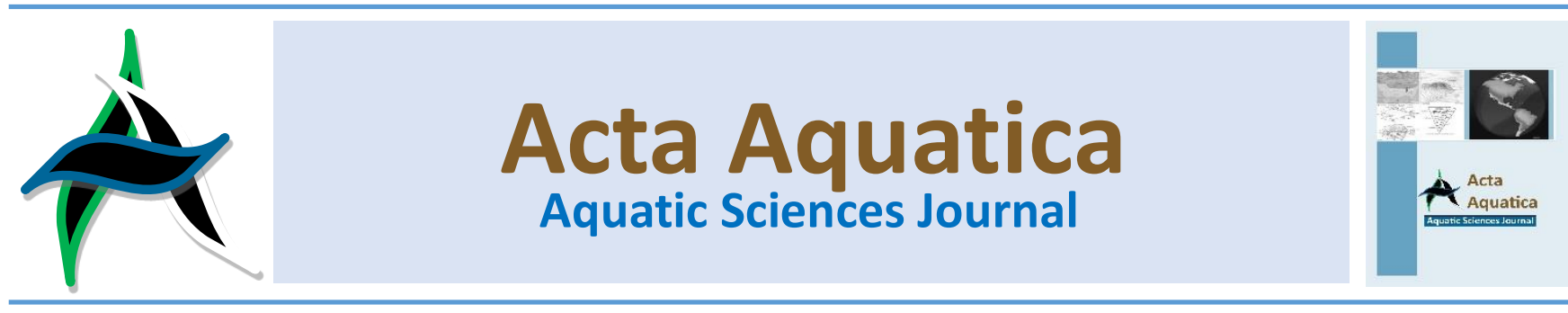

\title{
Pengaruh penurunan salinitas terhadap laju konsumsi oksigen dan pertumbuhan ikan kerapu lumpur (Epinephelus tauvina)
}

\section{The effect of declining salinity of on oxygen consumption rate and grouth rate of grouper (Epinephelus tauvina)}

\author{
Munawar Khalil a *, Ainol Mardhiah ${ }^{\text {a }}$ dan Rachmawaty Rusydi ${ }^{\text {a }}$ \\ a Program Studi Budidaya Perairan, Fakultas Pertanian, Universitas Malikussaleh
}

\begin{abstract}
Abstrak
Penelitian ini bertujuan untuk mengetahui pengaruh penurunan salinitas terhadap laju konsumsi oksigen dan pertumbuhan ikan kerapu lumpur (E. tauvina). Penelitian ini dilaksanakan pada tanggal 22 April sampai 22 Mei 2015 di Laboratorium Hatchery dan Teknologi Perikanan Program Studi Budidaya Perairan Fakultas Pertanian Universitas Malikussaleh. Rancangan penelitian yang digunakan adalah Rancangan Acak Lengkap (RAL) dengan lima perlakuan tiga ulangan dan dilanjutkan dengan Tukey jika terdapat perbedaan. Perlakuan yang diberikan yaitu : perlakuan A (27 ppt), B (24 ppt), C (21 ppt), D (18 ppt) dan E (15 ppt). Parameter yang diamati adalah laju konsumsi oksigen, pertambahan bobot, pertambahan panjang dan kelangsungan hidup. Hasil penelitian menunjukkan bahwa konsumsi oksigen tertinggi terdapat pada pelakuan $\mathrm{E}(15 \mathrm{ppt})$ yaitu $0,987 \pm 0,085$ $\mathrm{mgO}_{2} / \mathrm{gr} / \mathrm{jam}$ dan terendah pada perlakuan $\mathrm{A}(27 \mathrm{ppt})$ yaitu $0,612 \pm 0,033 \mathrm{mgO}_{2} / \mathrm{gr} / \mathrm{jam}$. Pertambahan bobot, panjang dan kelangsungan hidup tertinggi terdapat pada perlakuan $B(24 \mathrm{ppt})$ yaitu masing-masing sebesar $1,231 \pm 0,153$ gram, 0,970 $\pm 0,083 \mathrm{~cm}$ dan $90,476 \%$. Selama penelitian ini suhu bekisar antara 26,9$29^{\circ} \mathrm{C}, \mathrm{pH} 6,8-8,2$ dan DO 6,8-8,1 mg/ L.
\end{abstract}

Kata kunci: Kerapu; Kadar garam; Kondisi fisiologis

\begin{abstract}
The purpose of this study was to determine the effect of salinity reduction in the rate of oxygen consumption and growth grouper (E. tauvina). The research was conducted on April 22 to May 22, 2015. The research was conducted at the Laboratory of Aquatic Hatchery and Technology, Department of Aquaculture Faculty of Agriculture, University Malikussaleh. The study design used was completely randomized design (CRD) with three replication and five treatments followed by Tukey if there is a difference. The treatments were as follow: treatment A (27 ppt), B (24 ppt), C (21 ppt), D (18 ppt) and $E(15 \mathrm{ppt})$. Parameters measured were oxygen consumption rate, weight gain, length and survival rate. The results showed that oxygen consumption is highest in the carrying out of $\mathrm{E}(15 \mathrm{ppt})$ is $0,987 \pm 0,085 \mathrm{mgO}_{2} / \mathrm{gr} / \mathrm{h}$ and the lowest in treatment $A(27 \mathrm{ppt})$ is $0,612 \pm 0,033 \mathrm{mgO}_{2} / \mathrm{gr} / \mathrm{h}$. Weight gain, length and survival rate is highest in treatment $B(24 \mathrm{ppt})$ are respectively $1,231 \pm 0,153 \mathrm{gr}, 0,970 \pm 0,083 \mathrm{~cm}$ and $90,476 \%$. During this study the temperature ranged between $26,9-29^{\circ} \mathrm{C}$, $\mathrm{pH} 6,8-8,2$ and DO 6,8-8,1 $\mathrm{mg} / \mathrm{L}$.
\end{abstract}

Keywords: Grouper; Salinity; Physiological condition

\footnotetext{
* Korespondensi: Prodi Budidaya Perairan, Fakultas Pertanian, Universitas Malikussaleh. Kampus utama Reuleut, Kabupaten Aceh Utara, Aceh, Indonesia. Tel: +62-645-41373 Fax: +62-645-59089. e-mail:khalii@unimal.ac.id
}

\section{Pendahuluan}

Indonesia adalah produsen utama kerapu. Kerapu adalah ikan yang hidup di air yang berkadar garam tinggi (air laut) hingga air yang berkadar garam rendah (payau). Kerapu lumpur sering ditemukan pada hábitat berlumpur antara lain muara sungai, teluk dan daerah mangrove. Kerapu ini juga terkadang ditemukan masuk ke sungai. Tempat hidup kerapu muda hingga dewasa berada di dasar perairan, sedangkan telur dan larva bersifat pelagis. Kerapu Lumpur tergolong jenis ikan yang cukup luas salinitasnya yaitu berkisar antara 12-35 ppt. Salinitas ideal untuk pemeliharaan kerapu lumpur berkisar antara 22-32 ppt (Soemarjati et al., 2015). 
Produksi ikan kerapu budidaya cenderung menurun yakni pada tahun 2010 sebanyak 3.605 ton dan pada tahun 2011 produksi ikan kerapu lumpur mengalami penurunan menjadi 2.255 ton. Pada tahun 2012 yang lalu produksi ikan kerapu mencapai $1.204,1$ ton (KKP, 2012). Penurunan produksi ikan kerapu merupakan implikasi dari beberapa kendala pembudidayaan kerapu, seperti ketidaksesuaian lingkungan hidup, keterbatasan benih, penyakit dan sebagainya.

Kerapu merupakan ikan yang hidup di dasar perairan yang cukup dalam (pada kedalaman 70 meter) hingga dasar perairan dangkal atau di muara sungai. Faktor penting dalam aspek budidaya kerapu lumpur adalah menjaga kualitas air sebagai media benih maupun ikan kerapu dewasa agar tetap optimal untuk tumbuh dan berkembang. Kualitas air dapat dipengaruhi oleh berbagai faktor baik faktor fisika, biologi maupun kimia seperti temperatur, $\mathrm{pH}$, salinitas, oksigen terlarut, amoniak, nitrat dan nitrit maupun kelimpahan organisme air sebagai sumber makanan.

Salinitas merupakan salah satu faktor yang berpengaruh pada budidaya ikan kerapu. Salinitas berpengaruh secara langsung terhadap metabolisme tubuh ikan, terutama proses osmoregulasi (Gracia et al., 2006 dalam Yurisma et al., 2013). Salah satu aspek fisiologi ikan yang dipengaruhi oleh salinitas adalah tekanan osmotik dan konsentrasi cairan tubuh serta kebutuhan oksigen. Lingkungan perairan dengan perubahan salinitas dapat mempengaruhi laju konsumsi oksigen (LKO) ikan.

Dalam rangka untuk menentukan kelangsungan hidup ikan kerapu lumpur untuk budidaya, penting untuk mengetahui faktor-faktor yang menentukan produksinya. Konsumsi oksigen merupakan aspek fisiologi yang mempengaruhi kehidupan ikan. Tingkat konsumsi oksigen merupakan salah satu variabel fisiologis penting yang berpengaruh pada kelangsungan hidup dan pertumbuhan organisme (Kumlu et al., 2001 dalam Yurisma et al., 2013)

Pengetahuan tentang fisiologi ikan merupakan salah satu kunci dalam keberhasilan budidaya ikan, tentang hubungan faktor fisiologi dengan faktor lingkungan perlu dilakukan untuk menunjang produktivitas budidaya ikan kerapu lumpur ( $E$. tauvina). Oleh karena itu, penelitian ini dilakukan untuk mengetahui pengaruh penurunan salinitas terhadap laju konsumsi oksigen dan pertumbuhan ikan kerapu lumpur ( $E$. tauvina).

\section{Bahan dan metode}

\subsection{Waktu dan tempat}

Penelitian ini dilaksanakan pada tanggal 22 April sampai 22 Mei 2015. Penelitian ini dilakukan di Laboratorium Hatchery dan Teknologi Perairan, Program Studi Budidaya Perairan Fakultas Pertanian Universitas Malikussaleh.

\subsection{Bahan dan alat}

Bahan yang digunakan yaitu benih ikan kerapu lumpur, air tawar, air laut dan ikan rucah. Alat yang digunakan antara lain, ember sebanyak 30 buah, aerator, pH meter, DO meter, neraca analitik, serok ikan, penggaris, selang sifon, gelas ukur, pipet tetes, kamera dan terpal hitam.

\subsection{Metode dan rancangan penelitian}

Metode penelitian yang digunakan adalah metode eksperimen dengan menggunakan berbagai jenis salinitas yang berbeda pada setiap perlakuan. Hasil dari pengamatan dilakukan analisis secara statistik serta akan disajikan dalam bentuk tabel, grafik dan dijelaskan secara deskriptif.

Rancangan penelitian yang digunakan adalah Rancangan Acak Lengkap (RAL) non-faktorial dengan 5 perlakuan dan 3 ulangan. Perbedaan salinitas sebagai faktor perlakuan. Taraf dari perlakuan tersesbut adalah:

Perlakuan A = Salinitas $27 \mathrm{ppt}$

Perlakuan B $=$ Salinitas $24 \mathrm{ppt}$

Perlakuan $\mathrm{C}=$ Salinitas $21 \mathrm{ppt}$

Perlakuan $\mathrm{D}=$ Salinitas $18 \mathrm{ppt}$

Perlakuan $\mathrm{E}=$ Salinitas $15 \mathrm{ppt}$

\subsection{Prosedur kerja}

\subsubsection{Persiapan wadah}

Pelaksanaan penelitian ini diawali dengan mempersiapkan wadah berupa ember dengan diameter $28 \mathrm{~cm}$. Sebelum digunakan ember dibersihkan dengan air dan dikeringkan selama satu hari. Kemudian ember tersebut diisi air yang telah disesuaikan dengan masing-masing perlakuan sebanyak sepuluh liter. Jumlah ember yang digunakan sebanyak 15 buah dan dipasang selang aerasi.

\subsubsection{Persiapan air media}

Sumber air yang digunakan diambil dari sepanjang perairan laut Lancang Barat dan air tawar yang berasal dari laboratorium. Air laut diangkut menggunakan jerigen. Kemudian air tersebut disaring menggunakan planktonet, dan diendapkan selama satu hari. Setelah itu baru dilakukan pengenceran dengan menambahkan air tawar kedalam air laut.Untuk mendapatkan salinitas sesuai dengan perlakuan yang diinginkan, maka dilakukan pengenceran dengan menggunakan persamaan menurut Keenan (1990) yaitu:

$$
\mathrm{V} 1 . \mathrm{M} 1=\mathrm{V} 2 . \mathrm{M} 2
$$

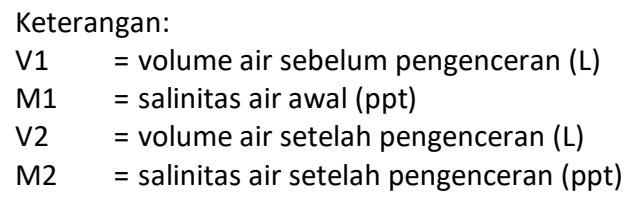

\subsubsection{Aklimatisasi}

Sebelum dilakukan penelitian benih terlebih dahulu diaklimatisasi yaitu penurunan salinitas sebanyak 3 ppt perhari yaitu pada pagi $1 \mathrm{ppt}$, siang $1 \mathrm{ppt}$ dan sore $1 \mathrm{ppt}$ agar benih dapat beradaptasi dengan air media yang digunakan. Aklimatisasi dilakukan selama 5 hari sebelum penelitian dimulai. Aklimatisasi bertujuan untuk adaptasi biota uji dengan lingkungan baru sehingga biota uji yang digunakan untuk penelitian tidak mengalami stres akibat perbedaan kondisi lingkungan yang baru dengan kondisi lingkungan asal biota uji yang digunakan. Pada saat aklimatisasi biota uji diberi pakan ikan rucah pada setiap pagi dan sore hari.

\subsubsection{Pemeliharaan biota uji}

Jumlah biota yang digunakan yaitu 105 ekor dengan panjang 6-7 cm, dimana tiap-tiap ember diisi 7 ekor ikan. Ikan yang akan dipelihara ditimbang terlebih dahulu untuk mengetahui berat awalnya. Selama pemeliharaan, ikan diberi pakan berupa ikan rucah. Pakan yang diberikan secara adlibitum 
yaitu pada pagi jam 08.00 WIB dan sore hari pada jam 17.00 WIB. Lamanya pemeliharaan selama satu bulan, pada saat pemeliharaan menggunakan aerasi.

\subsubsection{Media pemeliharaan}

Kualitas air pada setiap perlakuan harus dijaga sesuai dengan kadar optimalnya. Pengontrolan tingkat salinitas dilakukan secara berkala setiap hari. Pengelolaan kualitas air dilakukan dengan penyiponan guna membersihkan kotoran yang mengendap di dasar wadah. Penyiponan dilakukan dua kali sehari yaitu pada pagi dan sore hari sebelum pemberian pakan dan pergantian air sebanyak $20 \%$ dari keseluruhan air didalam wadah. Pada saat pemberian pakan wadah ditutup dengan menggunakan terpal hitam, ini dimaksudkan untuk memanipulasi lingkungan supaya kondisi menjadi gelap, karena ikan kerapu lumpur (E. tauvina) merupakan ikan nokturnal yaitu ikan yang aktif pada malam hari atau pada kondisi yang gelap.

\subsection{Parameter pengamatan}

\subsubsection{Laju konsumsi oksigen}

Pengamatan Laju Konsumsi Oksigen (LKO) pada ikan kerapu lumpur (Epinephelus tauvina) merupakan variabel yang dapat digunakan untuk menentukan laju metabolisme, ini berkaitan erat dengan pertumbuhan. Laju konsumsi oksigen dihitung dengan menggunakan persamaan menurut Rusdi dan Karim (2006) yaitu:

$$
\mathrm{LKO}=\mathrm{V} \times\left(\mathrm{DO}_{\mathrm{o}}-\mathrm{DO}_{\mathrm{t}}\right) / \mathrm{W} \times \mathrm{T}
$$

Keterangan:

LKO = laju konsumsi oksigen $\left(\mathrm{mgO}_{2} / \mathrm{g} / \mathrm{jam}\right)$

$\mathrm{V} \quad=$ volume air dalam wadah $(\mathrm{L})$

$\mathrm{DO}_{\mathrm{o}}=$ konsentrasi oksigen terlarut pada awal pengamatan $(\mathrm{mg} / \mathrm{L})$

$\mathrm{DO}_{\mathrm{t}}=$ konsentrasi oksigen terlarut pada waktu $\mathrm{t}(\mathrm{mg} / \mathrm{L})$

$\mathrm{W}=$ bobot total ikan (gram)

$\mathrm{T} \quad=$ periode pengamatan (jam)

Sebelum dilakukan pengukuran wadah yang telah diisi air dengan salinitas yang telah ditentukan diberi aerasi selama 24 jam agar oksigen dalam air jenuh. Setelah 24 jam aerasi pada wadah dimatikan, kemudian air dalam wadah yang telah diaerasi diukur DO awal. Sebelum ditebar ikan ditimbang bobotnya dengan menggunakan neraca analitik. Setelah itu ikan dimasukkan ke dalam wadah dengan hati-hati tanpa ada air yang memercik, wadah ditutup dengan terpal hitam, agar tidak ada kontak dengan udara luar selama 60 menit. Setelah 60 menit penutup terpal dibuka, lalu dimasukkan bagian ujung dari DO meter untuk mengukur oksigen terlarut pada media air wadah tersebut, penutup terpal hanya dibuka sesuai ukuran bagian ujung dari DO meter. Ini dimaksudkan supaya tidak masuknya oksigen dari luar. Pengukuran laju konsumsi oksigen diukur setiap 60 menit selama tiga jam. Pengukuran laju konsumsi oksigen pada ikan dilakukan setiap enam hari sekali dimulai pada pagi jam 09.00 WIB.

\subsubsection{Pertumbuhan dan kelangsungan hidup benih}

Pengamatan pertumbuhan benih ikan kerapu lumpur ( $E$. tauvina) dipastikan dengan mengukur bobot tubuh ikan menggunakan timbangan analitik. Berat awal $\left(W_{0}\right)$, diukur setelah benih ikan di aklimatisasi selama lima hari dalam media yang telah ditetapkan. Untuk memperoleh data pertumbuhan dilakukan pengukuran bobot dan panjang tubuh ikan yang diukur setiap enam hari sekali. Effendie (1997) menyatakan bahwa kelangsungan hidup, pertumbuhan ikan dapat dihitung menggunakan persamaan-persamaan sebagai berikut:

Pertambahan bobot

$$
W=W t-W_{0}
$$

Keterangan:

$\mathrm{W}$ = pertambahan berat mutlak (g)

Wo = berat hewan uji pada minggu awal penelitian (g)

$\mathrm{Wt}$ = berat hewan uji pada minggu akhir penelitian (g)

Pertambahan panjang (L)

$$
L=L t-L o
$$

Keterangan:

$\mathrm{L} \quad=$ pertambahan panjang $(\mathrm{cm})$
$\mathrm{Lo} \quad=$ panjang hewan uji pada minggu awal penelitian $(\mathrm{cm})$
$\mathrm{Lt} \quad=$ panjang hewan uji pada minggu akhir penelitian $(\mathrm{cm})$

Kelangsungan hidup (SR)

$$
\mathrm{SR}=(\mathrm{Nt} / \mathrm{No}) \times 100 \%
$$

Keterangan:

$\mathrm{SR}=$ kelangsungan hidup (\%)

No = jumlah ikan yang hidup pada minggu awal penelitian (ekor)

$\mathrm{Nt}=$ jumlah ikan yang hidup pada minggu akhir penelitian (ekor)

\subsubsection{Kualitas air}

Selain melakukan pengamatan terhadap laju konsumsi oksigen dan benih ikan, juga dilakukan pengamatan kualitas air. Parameter kualitas air yang diukur meliputi $\mathrm{pH}$, salinitas, suhu dan DO. Pengukuran kualitas air dilakukan setiap hari yaitu pada pagi jam 08.00 WIB dan sore pada pukul 17.00 WIB.

\subsection{Analisis data}

Data yang digunakan dalam penelitian ini yaitu menggunakan Rancangan Acak Lengkap (RAL) dengan lima perlakuan dan tiga kali ulangan dengan menggunakan IBM SPSS Statistics versi 20 . Model umum rancangan dalam penelitian ini sesuai dengan Sudjana (1991) adalah:

$$
Y i j=\mu+\tau i+\epsilon i j
$$

Dimana:

$\mathrm{Y}_{\mathrm{ij}} \quad=$ variabel yang diamati pada laju konsumsi oksigen benih ikan kerapu lumpur pada perlakuan ke-i $(i=1,2,3,4,5$ / $A, B, C, D, E)$ dan ulangan ke-j $(j=1,2,3)$

$\mu \quad=$ rata-rata umum

ii $=$ efek perlakuan ke-i

$\epsilon_{\mathrm{ij}}=$ keasalahan/galat

Dari hasil penelitian analisis dengan analysis of variance (anova), apabila menunjukkan $F_{\text {hitung }}>F_{\text {tabel }}$ (berpengaruh nyata), selanjutnya dilakukan uji lanjut dengan menggunakan Uji Tukey. Uji lanjut dilakukan untuk melihat perbedaan antar perlakuan. 


\section{Hasil dan pembahasan}

\subsection{Hasil}

\subsubsection{Laju konsumsi oksigen}

Hasil pengamatan terhadap laju konsumsi oksigen ikan kerapu lumpur (Epinephelus tauvina) selama penelitian dengan perlakuan A (27 ppt), B (24 ppt), C (21 ppt), D (18 ppt) dan E (15 ppt), menunjukkan nilai laju konsumsi oksigen terendah terdapat pada perlakuan A (27 ppt) dengan rataan LKO 0,612 $\pm 0,033$ $\mathrm{mgO}_{2} / \mathrm{gr} / \mathrm{jam}$ dan tertinggi pada perlakuan E (15 ppt) dengan rataan $\mathrm{LKO} 0,987 \pm 0,085 \mathrm{mgO}_{2} / \mathrm{gr} / \mathrm{jam}$.

Rata-rata nilai LKO pada tiap perlakuan mengalami penurunan dari hari ke- 6 sampai hari ke-30. Pada perlakuan A rata-rata nilai LKO pada hari ke-6 yaitu 0,752 $\pm 0,088 \mathrm{mgO}_{2} / \mathrm{gr} / \mathrm{jam}$ menurun hingga hari ke-30 dengan rata-rata konsumsi oksigen $0,557 \pm 0,041 \mathrm{mgO}_{2} / \mathrm{gr} / \mathrm{jam}$.

Rata-rata nilai konsumsi oksigen pada hari ke-6 untuk perlakuan $\mathrm{B}$ yaitu $0,824 \pm 0,105 \mathrm{mgO}_{2} / \mathrm{gr} / \mathrm{jam}$, perlakuan $\mathrm{C}$ yaitu $0,984 \pm 0,113 \mathrm{mgO}_{2} / \mathrm{gr} / \mathrm{jam}$, perlakuan $\mathrm{D}$ rata-rata $0,994 \pm 0,127$ $\mathrm{mgO}_{2} / \mathrm{gr} / \mathrm{jam}$ dan perlakuan E yaitu $1,119 \pm 0,122 \mathrm{mgO}_{2} / \mathrm{gr} / \mathrm{jam}$. Pada hari ke-30 nilai konsumsi oksigen rata-rata pada perlakuan $B$ yaitu $0,658 \pm 0,126 \mathrm{mgO}_{2} / \mathrm{gr} / \mathrm{jam}$, perlakuan C yaitu $0,731 \pm 0,101$ $\mathrm{mgO}_{2} / \mathrm{gr} / \mathrm{jam}$, perlakuan $\mathrm{D} 0,833 \pm 0,052 \quad \mathrm{mgO}_{2} / \mathrm{gr} / \mathrm{jam}$ dan perlakuan $\mathrm{E}$ yaitu $0,850 \pm 0,077 \quad \mathrm{mgO}_{2} / \mathrm{gr} / \mathrm{jam}$. Untuk lebih jelasnya rata-rata keseluruhan perlakuan dapat dilihat pada Gambar 1.

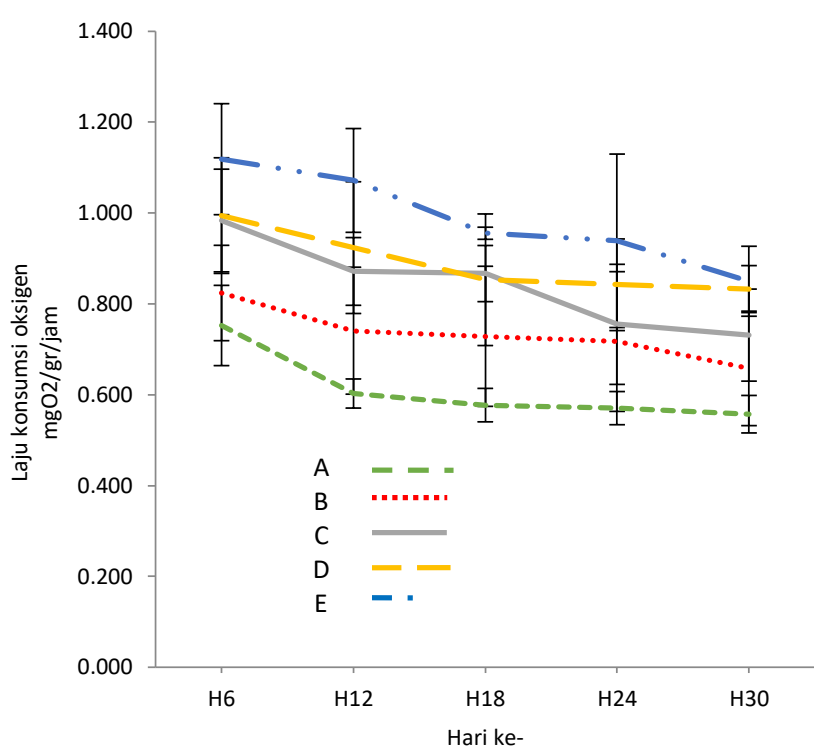

Gambar 1. Laju konsumsi oksigen pada ikan kerapu lumpur (E. tauvina). Ket. Perlakuan A: Salinitas $27 \mathrm{ppt,} \mathrm{Perlakuan} \mathrm{B:} \mathrm{Salinitas} 24 \mathrm{ppt}$ Perlakuan C: Salinitas 21 ppt, Perlakuan D: Salinitas 18 ppt, Perlakuan E: Salinitas 15 ppt.

Berdasarkan analisis ragam (ANOVA) menunjukkan bahwa pengaruh penurunan salinitas menunjukkan hasil yang berpengaruh sangat nyata terhadap laju konsumsi oksigen ikan kerapu lumpur (E. tauvina) dengan nilai $\mathrm{F}_{\text {hitung }} 7,758>\mathrm{F}_{\text {tabel }}(0,01)$ 5,99 . Setelah melakukan uji lanjut dengan menggunakan uji tukey, perlakuan A berbeda nyata dengan perlakuan E. Tabel 1 rataan konsumsi oksigen setiap perlakuan.
Tabel 1

Rataan konsumsi oksigen setiap perlakuan.

\begin{tabular}{lc}
\hline Perlakuan & Konsumsi oksigen $(\mathrm{mg} / \mathrm{L})$ \\
\hline A (27 ppt) & $0,612 \pm 0,033^{\mathrm{a}}$ \\
B (24 ppt) & $0,734 \pm 0,130^{\mathrm{ab}}$ \\
C (21 ppt) & $0,842 \pm 0,062^{\mathrm{ab}}$ \\
D (18 ppt) & $0,889 \pm 0,106^{\mathrm{ab}}$ \\
E (15 ppt) & $0,987 \pm 0,085^{\mathrm{b}}$ \\
\hline
\end{tabular}

Catatan: Huruf superscript menyatakan perlakuan yang berbeda pada selang kepercayaan $99 \%$

\subsubsection{Pertambahan bobot}

Hasil pengamatan terhadap pertambahan bobot ikan kerapu lumpur (Epinephelus tauvina) selama penelitian menunjukkan pertambahan bobot tertinggi didapati pada perlakuan $B$ dengan berat rata-rata 1,231 $\pm 0,153$ gram dan pertambahan bobot terendah pada perlakuan $E$ yaitu $0,592 \pm 0,084$ gram. Rata-rata pertambahan bobot pada perlakuan A yaitu 0,975 $\pm 0,141$ gram, pada perlakuan $C$ rata-rata pertambahan bobotnya $0,832 \pm 0,120$ gram dan perlakuan $D$ ratarata yaitu 0,694 $\pm 0,054$ gram. Untuk lebih jelasnya keseluruhan perlakuan dapat dilihat pada Gambar 2.

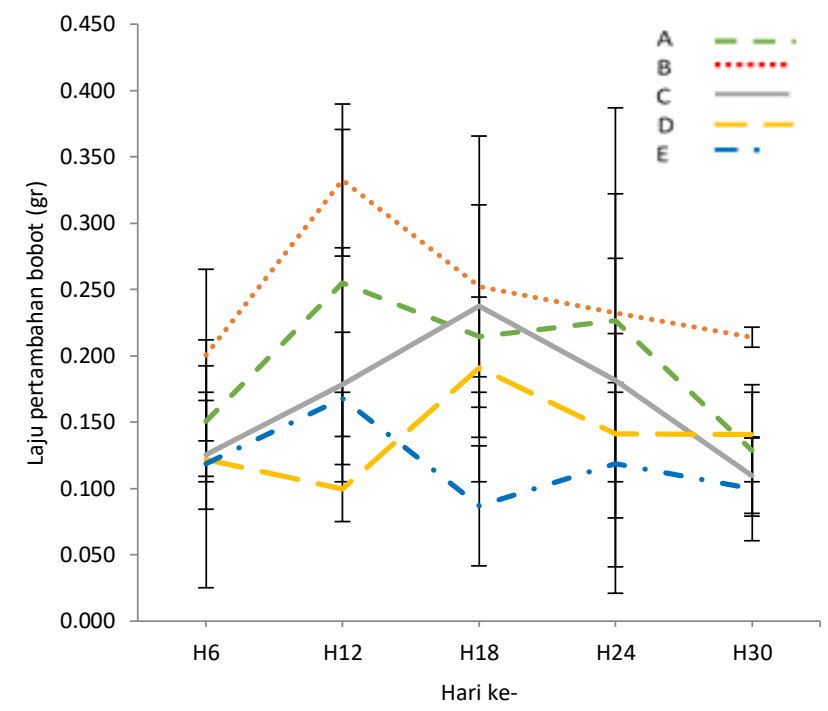

Gambar 2. Laju konsumsi pertambahan bobot (gram) pada ikan kerapu lumpur ( $E$ tauvina). Ket. Perlakuan A: Salinitas 27 ppt, Perlakuan B: Salinitas 24 ppt, Perlakuan C: Salinitas 21 ppt, Perlakuan D: Salinitas 18 ppt, Perlakuan E: Salinitas $15 \mathrm{ppt}$

Berdasarkan analisis ragam (ANOVA) menunjukkan bahwa pengaruh penurunan salinitas menunjukkan hasil yang berpengaruh sangat nyata terhadap pertambahan bobot tubuh ikan kerapu lumpur (E. tauvina) dengan nilai $F_{\text {hitung }} 13,930>F_{\text {tabel }}$ $(0,01)$ 5,99. Uji lanjut dengan menggunakan uji tukey menunjukkan bahwa bobot untuk perlakuan B berbeda nyata dengan perlakuan $\mathrm{D}$ dan E. Tabel 2 Rataan pertambahan bobot per perlakuan.

Tabel 2

Rataan Pertambahan Bobot Setiap Perlakuan

\begin{tabular}{lc}
\hline Perlakuan & Pertambahan bobot (gram) \\
\hline A (27 ppt) & $0,975 \pm 0,142^{\mathrm{ab}}$ \\
B (24 ppt) & $1,231 \pm 0,153^{\mathrm{a}}$ \\
C (21 ppt) & $0,832 \pm 0,120^{\mathrm{ab}}$ \\
D (18 ppt) & $0,694 \pm 0,054^{\mathrm{b}}$ \\
E (15 ppt) & $0,592 \pm 0,084^{\mathrm{b}}$ \\
\hline
\end{tabular}

Catatan: Huruf superscript menyatakan perlakuan yang berbeda pada selang kepercayaan $99 \%$ 


\subsubsection{Pertambahan panjang}

Hasil penelitian menunjukkan bahwa pertambahan panjang tertinggi terdapat pada perlakuan $\mathrm{B}$ dengan rata-rata pertambahan panjangnya $0,970 \pm 0,083 \mathrm{~cm}$ dan pertambahan panjang terendah pada perlakuan $E$ dengan rata-rata $0,473 \pm 0,030 \mathrm{~cm}$ (Gambar 3). Pada perlakuan A Rata-rata pertambahan panjangnya yaitu $0,767 \pm 0,032 \mathrm{~cm}$, perlakuan $C$ rata-rata $0,608 \pm 0,097 \mathrm{~cm}$ dan perlakuan $D$ dengan rata-rata pertambahan panjangnya yaitu 0,538 $\pm 0,079 \mathrm{~cm}$. Berikut grafik pertambahan panjang pada tiap perlakuan.

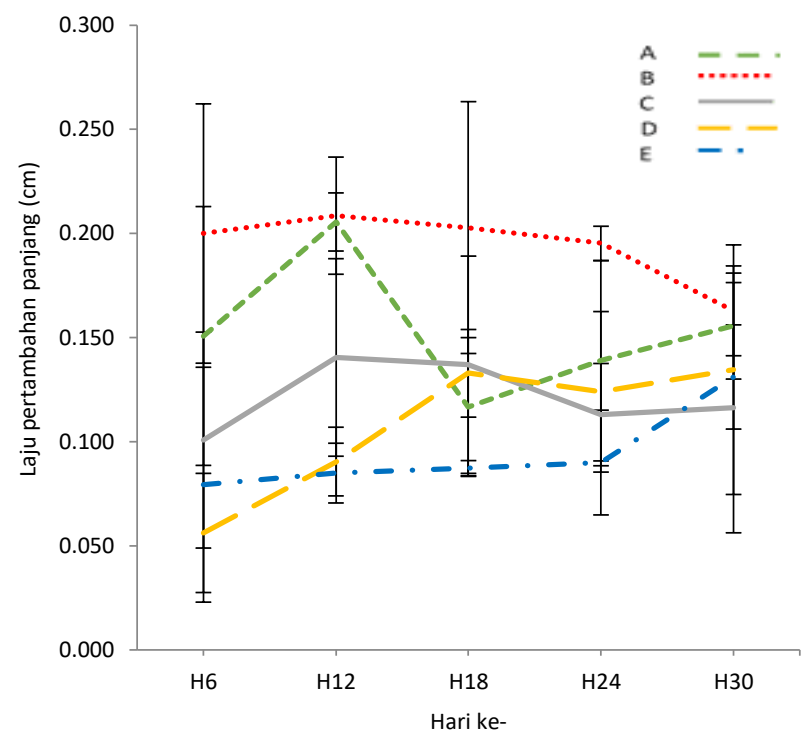

Gambar 3. Laju pertambahan panjang $(\mathrm{cm})$ pada ikan kerapu lumpur (E. tauvina) Ket. Perlakuan A: Salinitas 27 ppt, Perlakuan B: Salinitas 24 ppt, Perlakuan C: Salinitas 21 ppt, Perlakuan D: Salinitas 18 ppt, Perlakuan E: Salinitas 15 ppt.

Berdasarkan Uji ANOVA menunjukkan bahwa pengaruh penurunan salinitas menunjukkan hasil yang berpengaruh sangat nyata terhadap pertambahan panjang tubuh ikan kerapu lumpur (E. tauvina) dengan nilai $\mathrm{F}_{\text {hitung }} 24,440>\mathrm{F}_{\text {tabel }}(0,01) 5,99$. Uji lanjut dengan tukey menunjukkan bahwa perlakuan $A$ berbeda dengan perlakuan E. Perlakuan B berbeda dengan perlakuan C, D dan E. Berikut Tabel 3 rataan pertambahan panjang setiap perlakuan.

Tabel 3.

Rataan pertambahan panjang setiap perlakuan

\begin{tabular}{lc}
\hline Perlakuan & Pertambahan panjang $(\mathrm{cm})$ \\
\hline A (27 ppt) & $0,767 \pm 0,032^{\mathrm{ab}}$ \\
B (24 ppt) & $0,970 \pm 0,083^{\mathrm{a}}$ \\
C (21 ppt) & $0,608 \pm 0.097^{\mathrm{bc}}$ \\
D (18 ppt) & $0,538 \pm 0,079^{\mathrm{bc}}$ \\
E (15 ppt) & $0,473 \pm 0,030^{\mathrm{c}}$ \\
\hline
\end{tabular}

Catatan: Huruf superscript menyatakan perlakuan yang berbeda pada selang kepercayaan $99 \%$

\subsubsection{Tingkat kelangsungan hidup}

Hasil pengamatan tingkat kelangsungan hidup ikan Kerapu Lumpur (E. tauvina) selama 30 hari pemeliharaan dapat dilihat pada Gambar 4.

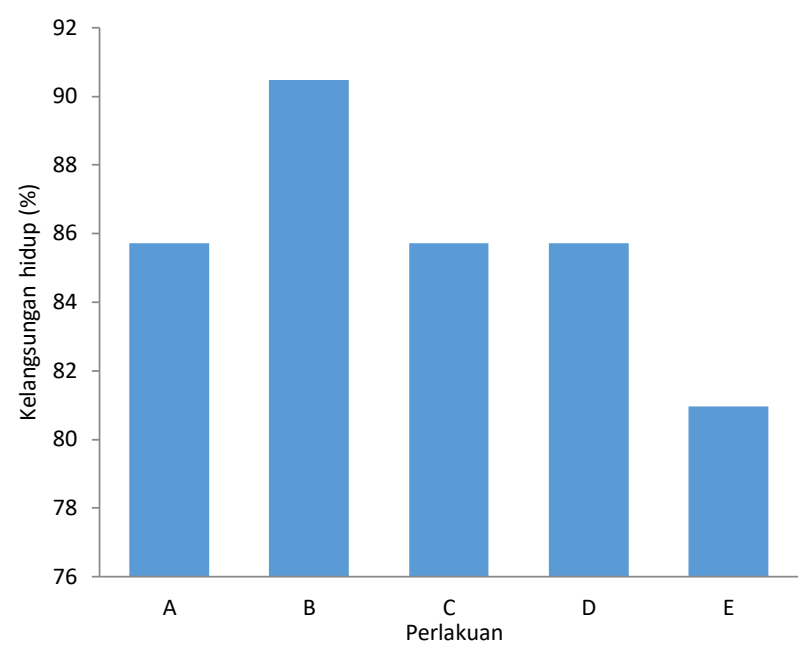

Gambar 4. Kelangsungan kerapu lumpur (E. tauvina). Ket. Perlakuan A: Salinitas 27 ppt, Perlakuan B: Salinitas 24 ppt, Perlakuan C: Salinitas 21 ppt, Perlakuan D: Salinitas 18 ppt, Perlakuan E: Salinitas 15 ppt.

Hasil menunjukkan bahwa rata-rata kelangsungan hidup ikan kerapu lumpur (E. tauvina) tertinggi dicapai pada perlakuan B yaitu sebesar 90,476 \%, di ikuti perlakuan A yaitu sebesar $85,714 \%$. Tingkat kelangsungan hidup perlakuan $C$ yaitu sebesar $85,714 \%$, perlakuan D yaitu sebesar $85,714 \%$, dan terakhir pada perlakuan E sebesar 80,952\%.

Hasil dari Uji ANOVA menunjukkan bahwa pengaruh penurunan salinitas menunjukkan hasil yang tidak berpengaruh nyata terhadap kelangsungan hidup ikan kerapu lumpur (Epinephelus tauvina) dengan nilai $F_{\text {hitung }} 0,227<F_{\text {tabel }}(0,05) 3,48$. Ini menunjukkan bahwa tingkat kelangsungan hidup antar perlakuan hampir sama.

\subsubsection{Kualitas air}

Berdasarkan hasil pengukuran kualitas air media pemeliharaan ikan kerapu lumpur (E. tauvina), secara umum berada pada kisaran optimal ikan kerapu lumpur untuk tumbuh. Nilai parameter kualitas air pada media pemeliharaan ikan kerapu lumpur (E. tauvina) dapat dilihat pada Tabel 4 berikut ini.

Tabel 4

Nilai parameter kualitas air pada media pemeliharaan ikan kerapu lumpur.

\begin{tabular}{lccc}
\hline Perlakuan & $\mathrm{pH}$ & Suhu $\left({ }^{\circ} \mathrm{C}\right)$ & $\mathrm{DO}(\mathrm{mg} / \mathrm{L})$ \\
\hline A & 7,31 & 27,86 & 7,46 \\
B & 7,35 & 27,87 & 7,47 \\
C & 7,34 & 27,87 & 7,49 \\
D & 7,35 & 27,85 & 7,49 \\
E & 7,36 & 27,83 & 7,48 \\
\hline
\end{tabular}

Fluktuasi $\mathrm{pH}$ terjadi dari hari ke hari pada hari pertama $\mathrm{pH}$ berkisar antara 7-7,47 dengan fluktuasi yang tidak terlalu drastis. Pada hari ke-9, pH berkisar antara 6,98-7,02. pH mulai meningkat pada hari ke-10, kemudian mulai menurun sedikit demi sedikit hingga hari ke-15 dengan $\mathrm{pH} 6,85-6,92$. Pada hari ke$17 \mathrm{pH}$ meningkat sampai 7,65-7,78, selanjutnya terjadi penurunan, dan sedikit meningkat kemudian menurun lagi sampai pada hari ke-30 dengan nilai pH 6,97-7,05.

Hasil penelitian menunjukkan bahwa suhu pemeliharaan ikan kerapu lumpur (E. tauvina) masih pada kisaran normal. Nilai suhu harian berkisar antara $27,25-28,50^{\circ} \mathrm{C}$. Pada hari pertama suhu berkisar antara $27,72-28,22^{\circ} \mathrm{C}$. Terjadi fluktuasi suhu, pada hari ke-10 suhu rata-rata $27,25-27,35^{\circ} \mathrm{C}$. Pada hari ke-28, suhu rata-rata $28,70-28,80^{\circ} \mathrm{C}$, kemudian menurun dan sedikit meningkat pada hari ke-30 dengan suhu $27,80-27,90^{\circ} \mathrm{C}$. 
Oksigen terlarut dari hasil penelitian rata-rata berkisar antara $6,77-7,92 \mathrm{mg} / \mathrm{L}$. Pada hari pertama oksigen terlarut ratarata 7,88-7,92 mg/L. Kandungan oksigen terlarut dalam air terus mengalami perubahan, oksigen terlarut terendah terdapat pada hari ke-13 dengan nilai oksigen terlarut rata-rata $6,77-7,05 \mathrm{mg} / \mathrm{L}$. Selanjutnya oksigen terlarut terus mengalami perubahan sampai hari ke-30 dengan kandungan oksigen terlarut 7,52-7,68 mg/L.

\subsection{Pembahasan}

\subsubsection{Laju konsumsi oksigen}

Laju konsumsi oksigen (LKO) adalah banyaknya oksigen yang diambil atau dikonsumsi oleh biota akuatik dalam waktu tertentu yang berhubungan dengan banyaknya oksigen terlarut. LKO merupakan salah satu parameter fisiologis yang dapat digunakan untuk menaksir laju metabolisme secara tidak langsung. Laju metabolisme biasanya diperkirakan dengan mengukur banyaknya oksigen yang dikonsumsi makhluk hidup per satuan waktu (Tobin, 2005 dalam Yurisma et al., 2013). Adapun faktor yang mempengaruhi LKO yaitu kandungan oksigen dalam air, waktu perhitungan laju konsumsi oksigen, volume air dalam wadah dan berat ikan. Apabila nilai dari faktorfaktor tersebut berubah maka nilai LKO pasti juga akan mengalami perubahan.

Ikan yang memiliki ukuran bobot kecil lebih banyak mengkonsumsi oksigen dibandingkan ikan berukuran bobot besar karena ikan ukuran kecil dapat melakukan osmoregulasi lebih banyak dan ikan ukuran kecil cenderung mengalami stress osmotik. Santoso dan Purwanto (2008) menyatakan bahwa laju konsumsi akan meningkat dengan kecilnya bobot ikan atau sebaliknya semakin berat ikan maka laju konsumsi oksigen semakin kecil.

Pengamatan LKO ikan kerapu lumpur (E. tauvina) selama 30 hari pemeliharaan menunjukkan bahwa nilai LKO terendah pada perlakuan A (27 ppt), yaitu sebesar 0,612 $\pm 0,033$ $\mathrm{mgO}_{2} / \mathrm{gr} / \mathrm{jam}$. Selanjutnya diikuti oleh perlakuan B (24 ppt) dengan rataan $\mathrm{LKO} 0,734 \pm 0,130 \mathrm{mgO}_{2} / \mathrm{gr} / \mathrm{jam}$, pada perlakuan $\mathrm{C}$ (21 ppt) dengan nilai $0,842 \pm 0,062 \mathrm{mgO}_{2} / \mathrm{gr} / \mathrm{jam}$, pada perlakuan D (18 ppt) dengan nilai $0,889 \pm 0,106 \mathrm{mgO}_{2} / \mathrm{gr} / \mathrm{jam}$, dan perlakuan $\mathrm{E}(18 \mathrm{ppt})$ dengan nilai $0,987 \pm 0,085 \mathrm{mgO}_{2} / \mathrm{gr} / \mathrm{jam}$.

Penurunan salinitas dapat mempengaruhi laju konsumsi oksigen. Perubahan salinitas terhadap ikan menyebabkan perubahan fisiologi osmoregulasi. Pada saat ikan memasuki lingkungan dengan salinitas yang berbeda dari habitat aslinya, maka ikan akan melakukan osmoregulasi untuk menyesuaikan kadar garam yang ada dalam tubuh dengan lingkungan. Ikan harus mampu menerima dan mengeluarkan kelebihan garam yang ada dalam tubuhnya, sehingga ikan membutuhkan energi yang mengakibatkan proses metabolismenya tinggi. Proses metabolisme yang tinggi pada ikan membuat ikan mengkonsumsi oksigen yang lebih tinggi. Oleh karena itu, ikan kerapu pada salinitas lebih rendah laju konsumsi oksigennya tinggi.

Semakin rendah salinitas laju konsumsi oksigen semakin tinggi hal ini disebabkan karena ikan pada salinitas rendah lebih banyak memerlukan energi untuk melakukan osmoregulasi. Semakin sering ikan melakukan osmoregulasi laju metabolismenya akan meningkat karena osmoregulasi membutuhkan energi, sedangkan energi dari makanan membutuhkan oksigen untuk mengoksidasi makanan sehingga akan meningkatkan konsumsi oksigen. Yurisma et al. (2013) menyatakan laju konsumsi oksigen (LKO) merupakan salah satu parameter fisiologis yang dapat digunakan untuk menaksir laju metabolisme secara tidak langsung, yaitu dengan mengukur oksigen yang digunakan dalam proses oksidasi.
Perubahan salinitas mempengaruhi tekanan osmotik cairan tubuh ikan, sehingga ikan melakukan osmoregulasi untuk mengatur konsentrasi cairan dan menyeimbangkan pemasukan serta pengeluaran cairan tubuh sehingga proses fisiologis dalam tubuh dapat bekerja secara normal lagi. Pada saat ikan melakukan osmoregulasi ikan membutuhkan banyak energi, konsumsi pakan akan meningkat, dengan demikian akan meningkatkan proses metabolisme pada ikan sehingga membuat ikan mengkonsumsi oksigen lebih banyak. Oksigen dibutuhkan oleh ikan untuk membantu proses metabolisme yang terjadi didalam tubuh (Fujaya, 2004).

\subsubsection{Pertumbuhan ikan uji}

Pertumbuhan merupakan suatu proses perubahan bobot dan ukuran tubuh dalam periode tertentu. Menurut Huet (1971) dalam Sari (2012), pertumbuhan dipengaruhi oleh faktor dalam dan faktor luar. Faktor dalam terdiri dari keturunan, ketahanan terhadap penyakit, kemampuan memanfaatkan pakan dan umur atau ukuran ikan, sedangkan faktor luar terdiri dari kualitas air, seperti suhu, oksigen terlarut dan $\mathrm{pH}$, kualitas pakan dan gerakan.

\section{Petumbuhan bobot}

Pertambahan bobot ikan kerapu lumpur (E. tauvina) selama 30 hari pemeliharaan berdasarkan Gambar 3. mengalami pertambahan bobot dengan nilai tertinggi dicapai pada perlakuan B (24 ppt), yaitu sebesar 0,246 gram. Selanjutnya diikuti oleh perlakuan $A$ (27 ppt) dengan nilai sebesar 0,195 gram. Pada perlakuan C (21 ppt) dengan nilai 0,166 gram, pada perlakuan $\mathrm{D}(18 \mathrm{ppt})$ dengan nilai 0,139 gram, dan perlakuan $\mathrm{E}$ (18 ppt) dengan nilai 0,118 gram.

Apabila salinitas berbeda jauh dengan tekanan osmotik cairan tubuh (kondisi tidak ideal) maka osmotik media akan berpengaruh terhadap ikan sehingga ikan membutuhkan energi yang relatif besar untuk mempertahankan osmotik tubuhnya agar tetap berada pada keadaan yang ideal. Jadi salinitas media akan mempengaruhi kebutuhan energi untuk osmoregulasi, yang disisi lain juga akan mempengaruhi tingkat konsumsi pakan. Dari penelitian ini dapat disimpulkan bahwa semakin rendah salinitas semakin tinggi tingkat metabolisme dan konsumsi oksigen pun semakin tinggi. Semakin rendah salinitas maka akan berpengaruh terhadap proses metabolisme yang membuat ikan membutuhkan energi lebih banyak sehingga ikan banyak mengkonsumsi pakan. Semakin tinggi laju metabolisme penggunaan energi dari pakan semakin tinggi, sehingga menyebabkan penimbunan energi untuk meningkatkan bobot semakin terbatas.

Semakin rendah salinitas media tidak memberikan pengaruh lebih baik terhadap pemanfaatan pakan ikan. Hal tersebut terlihat pada perlakuan $\mathrm{E}(15 \mathrm{ppt})$, lebih rendah dari $\mathrm{D}$ (18 ppt). Pertambahan bobot terendah pada perlakuan E (15 ppt) yaitu 0,118 gram. Hal ini disebabkan karena tekanan osmotik cairan tubuhnya lebih tinggi dibandingkan dengan tekanan osmotik media, akibatnya ikan cenderung banyak mengeluarkan energi untuk proses osmoregulasi.

Pertambahan bobot terbaik terdapat pada perlakuan B (24 ppt) yaitu 0,246 gram, karena dengan salinitas $24 \mathrm{ppt}$ tekanan osmotik pada tubuh hampir seimbang dengan tekanan osmotik media tempat hidupnya sehingga energi yang dibutuhkan tidak terlalu besar dan secara otomatis akan berpengaruh terhadap pemanfaatan pakan untuk pertumbuhannya.

Pertambahan bobot terbaik terdapat pada perlakuan B (24 ppt) hal ini juga dikarenakan ikan kerapu lumpur (E. tauvina) 
mampu menyesuaikan diri terhadap penurunan salinitas dan dapat memanfaatkan pakan dengan baik dan sesuai dengan kebutuhan ikan kerapu lumpur. Menurut Effendi (1979) dalam Sari (2012) ikan akan dapat tumbuh apabila pakan yang diperoleh baik kualitas maupun kuantitasnya telah melampaui keperluan untuk mempertahankan bobot dan panjangnya.

\section{Pertambahan panjang}

Pertambahan panjang ikan kerapu lumpur (E. tauvina) selama 30 hari pemeliharaan mengalami peningkatan. Panjang rata-rata tertinggi dicapai pada perlakuan $B$ (24 ppt), yaitu sebesar 0,194 cm, diikuti oleh perlakuan A (27 ppt) sebesar 0,153 $\mathrm{cm}$. Kemudian perlakuan C (21 ppt) menunjukkan pertambahan panjang sebesar $0,122 \mathrm{~cm}$, pada perlakuan $\mathrm{D}(18 \mathrm{ppt})$ sebesar $0,108 \mathrm{~cm}$ dan perlakuan terendah dicapai pada perlakuan E (15 ppt), yaitu sebesar $0,095 \mathrm{~cm}$.

Menurut Enggar (2009) dalam Sari (2012) menyatakan bahwa pertumbuhan panjang tubuh ikan seiring dengan pertumbuhan bobot tubuh ikan itu sendiri. Setiap pertambahan bobot ikan akan bertambah pula panjangnya. Penurunan salinitas memberikan pengaruh terhadap kinerja pertambahan panjang maupun pertambahan bobot. Pertambahan panjang tertinggi pada perlakuan $\mathrm{B}$. Hal ini disebabkan karena ikan masih dapat memanfaatkan pakan dengan baik untuk pertumbuhannya. Sedangkan pertambahan panjang terendah pada perlakuan E disebabkan karena ikan lebih banyak mengeluarkan energi untuk proses osmoregulasi.

\subsubsection{Tingkat kelangsungan hidup}

Tingkat kelangsungan hidup ikan adalah nilai presentase jumlah ikan hidup selama masa pemeliharaan pada waktu tertentu. Tingkat kelangsungan hidup ikan kerapu lumpur (Epinephelus tauvina) selama penelitian berkisar antara 80,952 $90,476 \%$. Tingkat kelangsungan hidup paling tinggi pada perlakuan B (24 ppt) disebabkan salinitas 24 ppt hampir sama dengan habitat aslinya karena salinitas yang sesuai dengan habitat aslinya akan mendukung kelangsungan hidup ikan.

Tingkat kelangsungan hidup terendah pada perlakuan $\mathrm{E}$ (15 ppt) hal ini disebabkan oleh kanibalisme karena berkompetisi dalam memperoleh makanan. Rendahnya salinitas mempengaruhi proses osmoregulasi dengan demikian proses metabolisme dalam tubuh pun semakin meningkat, banyaknya energi yang dibutuhkan untuk osmoregulasi sehingga ikan memerlukan banyak pakan sebagai sumber energi. Kekurangan pakan menyebabkan ikan bersifat kanibalisme. Menurut Kordi (2001) ikan kerapu memerlukan pakan untuk mempertahankan hidupnya dan jika ditinjau dari jenis pakan, ternyata hewan yang satu ini tergolong karnivora atau pemakan daging, bahkan cenderung memiliki sifat kanibalisme, artinya ikan kerapu yang lebih besar ukurannya bisa memangsa ikan sejenis yang lebih kecil.

\subsubsection{Kualitas air}

Selama penelitian diperoleh suhu pada pagi hari 27 - 29 ${ }^{\circ} \mathrm{C}$ dan pada sore hari suhu berkisar antara $26,9-28,5^{\circ} \mathrm{C}$. Hal ini sesuai dengan pernyataan Mansyur (1995) dalam Farabi, 2013, beberapa persyaratan kualitas air bagi kerapu lumpur antara lain: salinitas $15-35 \mathrm{ppt}$, suhu $24-35^{\circ} \mathrm{C}$.

Nilai $\mathrm{pH}$ media pemeliharaan $\mathrm{pH}$ pada pagi hari berkisar antara 6,8-8,2 dan pada sore hari berkisar antara 6,9-7,9. Hal tersebut tidak akan memberikan pengaruh negatif terhadap pertumbuhan ikan kerapu lumpur (E. tauvina), sehingga pembakaran makanan dengan bantuan oksigen dalam tubuh ikan akan tetap berjalan baik. Boyd (2000) dalam Farabi (2013) menyatakan bahwa nilai $\mathrm{pH}$ yang mematikan bagi ikan yaitu kurang dari 4 dan lebih dari 11, pada $\mathrm{pH}$ kurang dari 6,5 atau lebih dari 9,5 dalam waktu yang lama akan mempengaruhi pertumbuhan dan reproduksi ikan. Nilai $\mathrm{pH}$ optimal untuk ikan ada pada range 6,8 - 8,5 (Soemarjati et al., 2015).

Oksigen terlarut berkisar antara $6,8-8,1 \mathrm{mg} / \mathrm{L}$ pada pagi dan sore hari. Pengaruh oksigen terlarut sangat jelas terlihat pada kelangsungan hidup dan pertumbuhan. Kandungan oksigen dalam air antara 4-12 ppm dapat memberikan kondisi yang nyaman untuk pertumbuhan ikan kerapu (Mansyur, 1995 dalam Farabi, 2013). Selain itu dilakukan penyiponan setiap hari sebelum pemberian pakan yaitu pada pagi dan sore hari untuk membersihkan feses dan sisa-sisa makanan. Adanya penambahan aerasi yang cukup dapat membantu dalam menjaga kualitas air agar tetap normal.

\section{Kesimpulan}

Penurunan salinitas 27 ppt, 24 ppt, 21 ppt, 18 ppt dan 15 ppt berpengaruh sangat nyata terhadap laju konsumsi oksigen, pertambahan bobot dan panjang ikan kerapu lumpur (E.tauvina). Laju konsumsi oksigen tertinggi terdapat pada perlakuan E (15 ppt) dan terendah pada perlakuan A (27 ppt). Pertambahan panjang dan bobot tertinggi terdapat pada perlakuan B (24 ppt). Tingkat kelangsungan hidup ikan kerapu lumpur tertinggi terdapat pada perlakuan $\mathrm{B}(24 \mathrm{ppt})$. Kualitas air selama penelitian yaitu: Suhu $26,9-28,5^{\circ} \mathrm{C}$ dan pH 6,8 $-8,2$ dan DO $6,8-8,1 \mathrm{mg} / \mathrm{L}$.

\section{Bibliografi}

Effendi, M.I., 1997. Biologi Perikanan. Yayasan Pustaka Nusantara, Yogyakarta.

Farabi, M.I., 2013. Pengaruh Salinitas yang Berbeda Terhadap Pertumbuhan dan Kelangsungan Hidup Benih Ikan Kerapu Lumpur (Epinephelus tauvina). Skripsi. Tidak diterbitkan. Universitas Malikussaleh, Aceh Utara.

Fujaya, Y., 2004. Fisiologi Ikan Dasar Pengembangan Teknik Perikanan. Rineka Cipta, Jakarta.

Keenan, 1990. Kimia Untuk Universitas. Erlangga, Jakarta.

KKP, 2012. Buku Statistik Kelautan dan Perikanan.http://statistik.kkp.go.id/index.php/arsip/c/6 4/Buku statistik kelautan-dan perikanan-2012/?category id=3, (diakses pada 14 November 2014).

Kordi, 2001. Pembesaran Ikan Kerapu Bebek di Keramba Jaring Apung. Kanisius, Yogyakarta.

Rusdi, I., Karim, M.Y., 2006. Salinitas Optimum bagi Sintasan dan Pertumbuhan Crablet Kepiting Bakau (Scylla paramamosain). Jurnal Sains \& Teknologi, Vol.6 No.3.

Santoso, A.D., Purwanto, W., 2008. Perkiraan Padat Tebar Optimum Berdasarakan Kebutuhan Oksigen Terlarut pada Ikan Kerapu Tikus (Epinephelus cromileptes) dan Kerapu Macan (Epinephelus fuscogutattus). Jurnal Perikanan (J. Fish. Sci.)X (1): 93-100.

Sari, M., 2012. Pengaruh Pemotongan Sirip untuk Meningkatkan Pertumbuhan Benih Ikan Mas (Cyprinus carpio). Skripsi. Tidak diterbitkan. Universitas Malikussaleh, Aceh Utara. 
Soemarjati, W., Ahmad, B.M., Susiana, R., Saparinto, C., 2015. Bisnis dan Budidaya Kerapu. Penebar Swadaya, Jakarta.

Sudjana, 1991. Desain dan Analisis Eksperimen. Tarsito, Bandung.

Yurisma, E. H., Nurlita, A., Gunanti, M., 2013. Pengaruh Salinitas yang Berbeda terhadap Laju Konsumsi Oksigen Ikan Gurame (Osphronemus gouramy) Skala Laboratorium. Jurnal Sains dan Seni Vol.1, No.1. 